\title{
Computer Programs for Standardless Quantitative Analysis of Minerals Using the Full Powder Diffraction Profile
}

\author{
By J. C. Taylor \\ CSIRO, Division of Fuel Technology, PMB 7, Menai, NSW 2234, Australia
}

\begin{abstract}
A Fortran 77 computer program has been developed for the quantitative analysis of minerals by multiphase profile analysis of the complete powder diffraction pattern. Featured are full-matrix least-squares refinement of 14 Rietveld "instrumental parameters" (phase scales, asymmetry, preferred orientations (March model), linewidths, instrument zero, lineshapes and unit cell dimensions), Brindley particle absorption contrast factors and amorphicity corrections. The program uses a crystal structure Databank, which contains information on absorption coefficients, unit cell data and crystal structures for some 90 common minerals. New minerals can be easily added. Structure parameters are also refinable by a profile decomposition method using a program called STRUCT. The sum of the calculated patterns, derived from the crystal structure data, is fitted to the observed pattern by a program called TRACSCAL which runs in singlepass multiphase mode and, after the above corrections have been applied, the weight percentages of the component phases are calculated from the Rietveld scaling factors.

The program runs on an IBM-compatible AT computer with $640 \mathrm{~K}$ of RAM, on an extended memory AT, or a mainframe system. Examples of its use are given with standard mixtures and naturally occurring specimens. On an AT computer with $20 \mathrm{MHz}$ clock speed a scaling run, including data input, reading of the pattern, processing of (hkl) files, calculation of the profile and one cycle of least squares fitting takes about 30 seconds for binary standard mixtures and about 2.5 minutes for a 7-phase natural bauxite pattern containing 320 independent $(\mathrm{hk} l)$ reflections.
\end{abstract}

\section{Introduction}

Traditionally, X-ray diffraction quantitative analysis methods have involved the measurement of integrated intensity ratios of nearby resolved lines with standard calibration mixtures, the proximity in angle compensating for angular-dependent aberrations (see, for example, Klug and Alexander (1974), Nuffield (1966)). It is however tedious to make up standards for a variety of situations, while some aberrations, such as preferred orientation, may vary irregularly with angle. Because, in practice, intensity anomalies cannot be completely removed experimentally, quantitative X-ray diffraction methods have previously been regarded as unreliable.

After Rietveld (1969) addressed the problem of line overlap in considering the complete diffraction profile there appeared some hope that measured full profiles could be replicated with calculated patterns. Full profiling has the advantage that residual errors, caused by intensity aberrations not completely removed in the specimen preparation stage, or imperfect structural models, tend to be positive and negative over the whole pattern leaving the Rietveld phase scaling factors largely unchanged. Rietveld (1969) gave a formula for the height $y_{i}$ of any point $i$ in the backgroundcorrected pattern profile of a single phase, and devised a computer program for structural refinement from the single-phase powder data profile.

Full-profile mainframe computer programs for singlephase powder data refinement now available include those of Rietveld (1969), Hewat (1973) (a modification of Rietveld's program), Wiles and Young (1981) and Will, Huang and Parrish (1983). The Wiles-Young program, multiphase for a limited number of phases, was given extended dimensions by Hill and Howard (1986) and used for quantitative phase analysis with neutron powder data (Hill and Howard (1987)) and neutron and X-ray powder data (Howard, Hill and Sufi (1988)), and also by Bish and Howard (1988). Hill and Howard (1987) also derived a simple relation between the Rietveld scaling factor of a phase and its mass in the sample. The above programs were originally developed for single-phase structural analysis with powder data, with coding not readily scaled down for small computers. They also did not have some of the correction functions needed for quantitative analysis. For example, the Rietveld (1969) preferred orientation correction of the form $\exp \left(-\mathrm{G} \alpha^{2}\right)$ was not properly normalised. The modified Wiles-Young program (Hill and Howard, 1986) has the March function (Dollase, 1986) which is correctly normalised; this function was also used in the present program.

Hill and Howard (1987) gave a summary of the status of $\mathrm{X}$-ray diffraction quantitative analysis at that time. Until full profiles were considered, it was thought that reliable quantification of ores by this method was not possible, because of the severe problems of overlap, preferred orientation amorphicity and absorption. The present system adresses these problems and it is shown by analysis of standard mixtures below that, even with extreme orientation or absorption contrast, good results can be obtained with careful specimen preparation. Amorphicity can be measured by adding a new spike phase, but the method cannot distinguish between amorphicity in the list of known phases, or amorphicity due to a further unlisted phase.

Smith et al., (1987) described a full-profile quantitative XRD system which compared measured standard patterns with the observed profile. This still had some of the drawbacks of the old standard-mixture technique as it was necessary to find pure standard materials. Changing line-widths and preferred orientation were also not easily corrected for. It is preferable to use calculated patterns and then correct for these effects theoretically by refinement.

Matrix absorption effects in powder X-ray diffraction quantitative analysis cannot be ignored (except in the case of neutron diffraction; here the absorption coefficients are nearly zero). The theory of Brindley (1945), summarised in Taylor (1961), showed that a particle absorption contrast correction factor, $\tau_{\mathrm{i}}$ could be derived for each phase $\mathrm{i}$, using assumed particle radii $R_{i}$. The $\tau_{\mathrm{i}}$ factors could be made closer to 1.0 by grinding to a fine powder, while the $R_{i}$ values could be estimated for standard mixtures ground under 
specified conditions. For careful hand grinding, $\mathbf{R}_{\mathrm{i}}$ could be assumed to be about $5 \mu \mathrm{m}$ (see examples under "Tests and Applications" below), except when the powder was already finer than this (when the Brindley factor then became less important). For an extreme example, a mixture of $\mathrm{Pb}\left(\mathrm{NO}_{3}\right)_{2}$ and LiF, Table 3 below, the $\tau$ factors for $\mathrm{CoK}_{\alpha}$ radiation were 0.588 and 1.122 , but the quantification was correct with $\mathrm{R}_{1}=\mathrm{R}_{2}=4.4 \mu \mathrm{m}$.

As the programs now available for quantitative XRD analysis, such as the Wiles-Young program, did not contain the physical corrections desired, and were written for mainframe structural refinement with single-phase patterns, the present program system was developed, in modular form with concise, efficient Fortran 77 code, suitable also for personal computing environments.

\section{Theoretical}

The intensity of one line of a phase A ( $\mathrm{K}$ is used to denote the triplet $(\mathrm{hkl}))$ is given by:

$$
I_{\mathrm{K}(\mathrm{A})} \propto V_{\mathrm{A}} J_{\mathrm{K}(\mathrm{A})} \frac{\mathrm{F}_{\mathrm{K}(\mathrm{A})}^{2}}{\mathrm{~V}_{\mathrm{C}(\mathrm{A})}^{2}}\left(\frac{1+\operatorname{Cos}^{2} 2 \theta \operatorname{Cos}^{2} 2 \theta_{\mathrm{m}}}{\sin 2 \theta \operatorname{Cos} \theta}\right) \tau_{\mathrm{A}}
$$

where $V_{A}$ is the volume of $A, J$ is the multiplicity, $F$ the structure factor, $V_{C}$ the unit cell volume, $\tau_{A}$ the Brindley (1945) particle absorption contrast factor, and the angular factor, which will be called ANG, covers the Lorentz and polarisation effects. Brindley (1945) gave

$$
\tau_{A}=\frac{1}{V} \int_{o}^{V} \exp \left(-\left(\mu_{A}-\tilde{\mu}\right)\right) x d v
$$

where $\mathrm{V}$ is a particle volume and $\mu$ is the linear absorption coefficient of the matrix (no voids).

For a two-phase mixture, of $\mathrm{A}$ and $\mathrm{B}$, equations of type (1) for two nearby resolved lines give, after some manipulation

$$
w \%(A)=100\left(1+\frac{I_{B} \rho_{B} V_{B}^{2} \tau_{A} J_{A} F_{A}^{2}(A N G)_{A}}{I_{A} \rho_{a} V_{A}^{2} \tau_{B} J_{B} F_{B}^{2}(A N G)_{B}}\right)
$$

This former method of comparing nearby lines is tedious and unreliable except for simple well-resolved patterns showing no orientation. To extend to the whole profile, we use the formula for the intensity of a background-corrected point on the profile given by Rietveld (1969) for phase A:

$$
\begin{aligned}
& Y i(\text { calc })=\text { Scale }_{A} \frac{1}{\tau_{\mathrm{A}}} \sum_{\mathrm{K}(\mathrm{A})} J_{K(A)} F_{K(A)}^{2}(\mathrm{ANG})_{\mathrm{A}} \\
& \frac{A S Y M}{H_{K(A)}} \cdot P R E F_{K(A)} . S H A P E_{K(A)^{\circ}}
\end{aligned}
$$

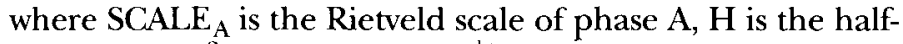
width, (U $\left.\tan ^{2} \theta+V \tan \theta+W\right)^{1 / 2}$, of the line $\mathrm{K}(\mathrm{A}), \mathrm{ASYM}$ is the Rietveld (1969) line asymmetry function (ASYM can usually be defaulted at a value of 0.2 ) and SHAPE is a line-shape function. We have now added the important factor $\tau_{\mathrm{A}}$ omitted by previous workers. To make this expression multiphase, we write

$$
Y_{i}(\text { total }, \text { calc })=\sum_{j=1}^{N} Y_{j}(\text { calc })
$$

where $\mathrm{N}$ is the number of phases. This equation is nonlinear in the variable parameters, but can be linearised by the Taylor expansion and least squares refinement done on the shifts (Hamilton, 1964; Taylor, 1980).

The present system differs from the original Rietveld (1969) paper in the functions PREF and SHAPE. The Rietveld exponential function is replaced by the March function:

$$
\operatorname{PREF}_{K(A)}=\left(r^{2} \cos ^{2} \alpha+\sin ^{2} \alpha / r\right)^{-3 / 2}
$$

with the refinable orientation parameter $\mathrm{r}(<1$ for plates, $>1$ for rods, Dollase (1986)). $\alpha$ is the angle between the plane normals of the plane $\mathrm{K}$ and the orientation plane. The usual multiplicities are broken down into submultiplicities of equivalent $\alpha$.

SHAPE is chosen as the Pearson VII distribution given as (Hall et al., 1977):

$$
\text { Shape }_{\mathbf{K}(\mathrm{A})}=\left(1+4\left(2^{\frac{1}{\mathrm{~m}}}-1\right) \frac{\left(2 \theta_{i}-2 \theta_{k}\right)^{2}}{H_{k}^{2}}\right)^{-m}
$$

The refinable parameter here is $m$, which is 1 for Cauchy, 2 for modified Lorentzian and $\infty$ for Gaussian. For Bragg-Brentano diffractometers, $m(A)$ is usually between 1 and 2, averaging about 1.5, while for neutron diffractometers $m$ is a larger number, say 5 to 10 .

In Rietveld's (1969) paper, refinable "instrumental" (as distinguished from "structural") parameters were instrument zero, asymmetry (both in the present system made global), and SCALE(A), $\operatorname{PREF}(A), U(A), V(A), W(A)$, and the unit cell dimensions. These are all refinable parameters in the present system. In most quantitative analysis applications, the crystal structures of the phases can be regarded as well-known and thus structural parameters generally will not need to be refined. The crystal structures are part of the supporting data in the Databank.

Once the instrumental variables have been found by least-squares fitting, then quantification is obtained by a cycle refining the scale factors of the phases only. Then:

$$
w \%(\mathrm{~A})=\frac{S C A L E_{A}(M V)_{A}}{\tau_{A}}\left(\sum_{j=1}^{N} \frac{S C A L E_{A}(M V)_{A}}{\tau_{j}}\right)^{-1}
$$

MV is the product of the unit cell masses and volumes.

\section{Correction Factors in the System}

(a) Absorption Contrast Factors, $\tau_{A}$

The basic theory of absorption contrast is given in Brindley (1945) and modified by de Wolff (1947) and Wilchinsky (1951) for very coarse powders. A useful summary is given in Taylor (1961). The Brindley treatment is appropriate for powders of fine to medium grade, and this is attainable in practically all cases by careful specimen preparation with fine grinding. Thus, the Brindley formula, (2) above, is of general use and is used here.

The examples given in the Test and Applications Sec- 
tion below show the reliability and importance of the Brindley correction. With extreme contrast (See Table 3), the $\tau$ factors are quite different to 1.0 but still give good quantitative analysis results.

When phases have like absorption (e.g. polymorphs of zirconia, zeolites, or in all neutron diffraction cases) the $\tau$ factors will be nearly unity. However, in most X-ray diffraction cases, the factors will differ significantly from 1.0 , and the Brindley theory should be applied. Brindley $\tau$ factors were previously used by the author (Taylor, Kelly and Downer, 1972) for the X-ray powder diffraction quantitative analysis of uranyl hydroxide polymorphs with different densities.

The only data that need to be fed into the program system to apply Brindley corrections are the effective particle radii, $R_{A}$ of the phases. For mortar-and-pestle grinding $R_{A}$ is found in practice to be about $5 \pm 1 \mu \mathrm{m}$, except when the sample is already finer than this (See Table 3).

\section{(b) Preferred Orientation Corrections}

The March function preferred orientation correction, with the refinable parameter $r$, (Equation (6) above) is built into the present program system. Inspection of the lines in the pattern may show an anomalously high intensity for a particular plane $K$. The indices of $K$ are then fed into the program, as the orientation plane $(r<1)$. Alternatively the intensity distribution, with an important line and anomalously low in intensity, may suggest rod-like morphology with the rod plane being the plane with low intensity. The rod plane is then used as the orientation plane $(r>1)$.

If the above procedures still do not work, there may be more than one orientation plane. In this case it is probably best to regrind the sample more finely, mix with a binder and pack the sample more loosely, in the hope of experimentally reducing the effect.

\section{(c) Amorphicity Corrections}

An amorphous phase is defined here as one in which the particle sizes are too small or the structure too disordered (e.g. glassy phases), to give sharp, measurable diffraction lines. Amorphous phases cannot be detected by X-ray diffraction, except indirectly by adding a known weight fraction of a spike phase. The presence of amorphous material obviously affects the quantification of mixtures.

Two kinds of amorphicity are distinguished in the present system:

(i) Amorphic content due to an extraneous phase. For example, a zeolite mineral containing measurable heulandite and chabazite may contain glassy quartz.

(ii) Amorphicity of phases in the list of phases present. To get correct quantification it may be necessary to assign some amorphic content to phases already having measurable lines. An example of this would be a rutile-zircon mixture with, say, $2 \%$ of the rutile as amorphous material. Other techniques for chemical analysis (e.g. XRF) may help in showing which phases have an amorphous content.

The two types of amorphicity are entered as program data. The matrix absorption is adjusted for the amorphous content to give the correct Brindley factors.

The program may be used to determine the amor- phous content of any mineral, by adding a spike of known weight percentage of an additional phase. The weight percentage of the spike phase will be calculated too low if there is amorphous phase present, and the amorphous content can be computed. The spike method will not, however, tell us whether the amorphicity is of type (i) or type (ii) above.

\section{Overview of the Programs}

A simplified flow diagram of the programs* ${ }^{*}$ is given in Figure 1. Details are given below.

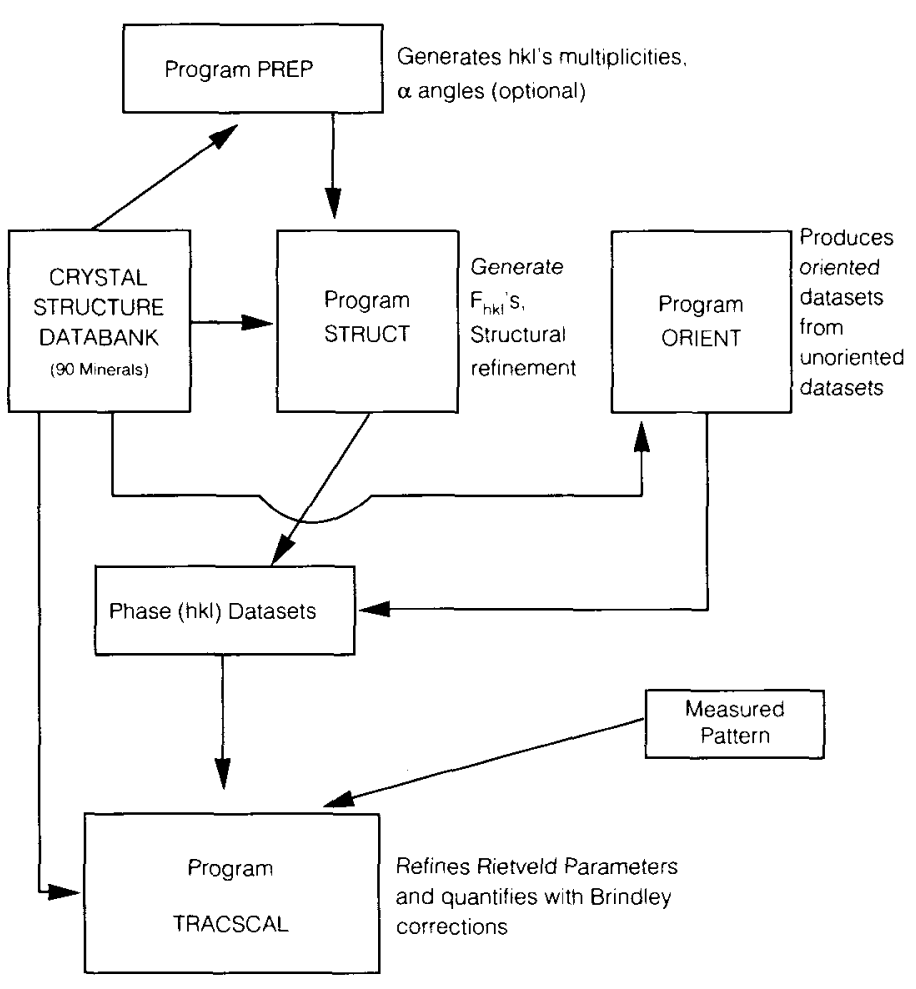

Figure 1. Flow Diagram of Program System.

\section{Program PREP}

PREP is an extension of a previous program for generating the multiplicities of crystal forms by computing the whole reciprocal lattice of a phase and grouping reflections of similar $2 \theta$ and $F_{k}$ (Taylor, 1978).

Optionally, PREP can be given a preferred orientation plane for the phase, and the program then sorts on $\alpha_{\mathrm{k}}$ as well. PREP is written in double precision.

\section{Program STRUCT}

STRUCT calculates structure factors $F_{k}$ from the structural information in the Crystal Structure Databank. STRUCT takes the $(\mathrm{hk} l)$ information generated by PREP and produces an (hkl) dataset for a phase, listing all (hk $l), \mathrm{F}_{\mathrm{k}}, \mathrm{J}_{\mathrm{k}}$, and $\alpha_{\mathrm{k}}$ for use in the main program TRACSCAL. A (hkl) dataset need only be computed once for a mineral (except

${ }^{1}$ The complete program system has now been called SIROQUANT (C) 1989 CSIRO. and is now being marketed by SIETRONICS Pty I.td, 18 Walder St., Belconnen, ACT, Australia. 
when the orientation plane is changed).

STRUCT can also be used to adjust the structural parameters of a phase by least-squares to fit the observed pattern. In this case, the program uses $F_{k}$ (obs) values which are extracted in program TRACSCAL (see below) by point-bypoint decomposition of the observed profile by the formula of Rietveld (1969):

$$
I_{k}(o b s)=\sum_{\mathrm{j}}\left(w_{j},{ }_{k} F_{K}^{2}(c a l c) \cdot y_{j}(o b s) / y_{j}(c a l c) .\right\}
$$

from which $F_{k}$ (obs) follows. This procedure has some advantages:

a) The $F_{k}$ (obs) values can be fed into single-crystal refinement programs like SHELX (Sheldrick, 1975), which have powerful geometrical constraints, as well as into STRUCT which also has geometrical constraints. This method has been found useful in refining very large zeolite structures from X-ray powder diffraction data (Taylor et al., 1986; Taylor, 1987a). The method reduces the data for the structural refinement to quasi single crystal data.

b) The weighting scheme of the extracted data is more like the single-crystal case than profile point weights.

Decomposition methods which do not use the calculated structural model are only possible for simple patterns. Although the calculated model is used in this decomposition, one must also start with a calculated model in other refinement methods. It has been shown (Taylor, 1987b) that iterations with the Rietveld decomposition formula and the conventional one-stage Rietveld process give the same structural parameters for a series of single-phase powder patterns. In STRUCT, the variable structural parameters are $x, y, z$, occupancy, and isotropic $U$ values of the atoms.

\section{Program ORIENT}

PROGRAM ORIENT allows a number of different oriented $(\mathrm{hk} l)$ datasets to be produced for TRACSCAL from a single unoriented $(\mathrm{hk} l)$ dataset from a PREP, STRUCT run. ORIENT takes the unoriented $(\mathrm{hk} l)$ data set and produces an oriented $(\mathrm{hk} l)$ dataset given the Databank number of the phase and the orientation plane. A backup copy of the unoriented dataset is kept in case other orientations need to be tried. If more than one orientation of a phase is tested, ORIENT is quicker than running PREP and STRUCT.

\section{Program TRACSCAL}

TRACSCAL is the main program in the system. TRACSCAL allows multiphase refinement of the following variables to fit a total calculated profile to the measured profile:

a) Global: instrument zero, line asymmetry.

b) Phase: scale, March $\mathrm{r}$ factor, U, V, W line-width parameters, Pearson VII shape-factor and unit cell dimensions $\mathrm{a}, \mathrm{b}, \mathrm{c}, \alpha, \beta, \gamma$.

Table 1 shows the dimensions allowed in TRACSCAL for the $640 \mathrm{~K}$ and $1000 \mathrm{~K}$ extended memory versions. TRACSCAL reads the measured pattern, corrects for background and then processes the $(\mathrm{hk} l)$ files of the phases, before leastsquares refinement. The more dominant parameters (instrument zero, phase scales and widths, and perhaps orientation) are refined with TRACSCAL first.
Table 1.

Dimensions in TRACSCAL

$\begin{array}{lcc}\text { Version } & \text { Normal }(640 \mathrm{k}) & \text { Extended Memory } \\ \text { \# Phases } & 8 & 11 \\ \text { \# LS Variables/Cycle } & 7 & 10 \\ \text { \# Pattern Points } & 3000 & 5000 \\ \text { \# hkl for a mineral } & 400 & 650\end{array}$

In refining the linewidths, only $\mathrm{W}$ is refined at first (taking $\mathrm{W}=\mathrm{H}_{\mathrm{K}}^{2}$ ) and then $\mathrm{U}$ and $\mathrm{V}$ are refined later if the data justifies it.

TRACSCAL can produce a difference pattern for study with Search-Match routines, for identification of minor phases.

As with any least-squares process, care must be taken to not refine parameters which are "too far away", or refine parameters which may be in some cases, ill-defined (e.g. sometimes $\mathrm{V}$ and $\mathrm{W}$ ). The residuals will then diverge instead of reduce, and the process must then be restarted.

TRACSCAL also has some other useful features:

a) $(\mathrm{hk} l)$ bars on the plots with their correct intensity heights aid in line identification and checking for orientation anomalies.

b) An automatic pre-scaling feature allows selection of an overall starting scale (500 to several thousand depending on the complexity of the pattern) which is input with initial estimates of the weight percentages. If these percentages are correct, the relative starting scale factors displayed on the screen will be correct, and only the overall scale will need adjusting from an initial run with no cycles of least-squares.

c) Damping factors DAMP on the shifts stop large oscillations when refinement starts from "far-off" values and will sometimes cause a refinement to succeed, when it would not with DAMP $=1.0$. Suggested DAMP values are 0.8 (always) and 0.3 for initial refinements of $\mathrm{U}, \mathrm{V}$ and $\mathrm{W}$ simultaneously.

d) TRACSCAL allows for any number of "Brindley Trials", with different particle radii $\mathrm{R}_{\mathrm{i}}$ or with different input weight fractions. $R_{i}=5.0 \mu \mathrm{m}$ is a good value for handground samples, but other values may be of interest to test the effect of the $R_{i}$ on the quantification. The $R_{i}$ values do not have to be the same for all phases in a sample.

(e) Diffractometer Calibration. If Guinier or DebyeScherrer data is used, then absorption corrections will need to be applied. These can be inserted in TRACSCAL through a correction-factor table which is a list of CORFAC $(\mathrm{i}), 2 \theta(\mathrm{i})$ for various $2 \theta$ values $i$. Also, if no automatic divergence slit is used with a Bragg-Brentano machine, a calibration for illumination area can be inserted. Various corrections can be combined into the one calibration curve. The measured pattern is corrected with this curve.

(f) Excluded Regions. TRACSCAL allows up to 30 "excluded regions" in which the value of the data may be dubious. format.

(g) Free Format. The programs have data input in free

\section{Crystal Structure Databank}

The Crystal Structure Databank contains structural, unit 
cell, and absorption coefficient data for 95 minerals belonging to families such as beach sands, bauxites, cements, zeolites, feldspars, ordered clay-types, micas, and so on. Other minerals are readily added. For each mineral is tabulated:

Unit cell mass volume and density, $\left(\frac{\mu}{\rho}\right)$ for various wavelengths, unit cell dimensions, symmetry information, atom coordinates, occupancies and temperature factors and scattering factors. The Databank is drawn on by all programs in the system.

\section{Tests and Applications}

The program system has been tested on a series of synthetic, weighed mixtures and other samples including natural minerals. The samples were Analar reagents or museum minerals and their purity was checked by X-ray diffraction. The X-ray diffraction data were collected on a Bragg-Brentano diffractometer under the conditions shown in Table 2.

Table 2.

Data Collection Conditions for the Patterns. (All patterns were taken with $\mathrm{CoK} \alpha$, except for Pure Rutile)

\begin{tabular}{|c|c|c|c|c|c|}
\hline Sample & $\begin{array}{l}\text { Start } \\
(2 \theta)\end{array}$ & $\begin{array}{l}\text { Finish } \\
(2 \theta)\end{array}$ & $\begin{array}{l}\text { Step } \\
(2 \theta)\end{array}$ & $\begin{array}{l}\text { Count } \\
\text { Time } \\
\text { (sec) }\end{array}$ & $\begin{array}{l}\text { No. of } \\
\text { Points }\end{array}$ \\
\hline $\mathrm{LiF}, \mathrm{Pb}\left(\mathrm{NO}_{3}\right)_{2}$ & 21.0 & 105.0 & .035 & 1 & 2401 \\
\hline $\begin{array}{l}\text { Rutile, Zircon, } \\
\text { Ilmenite }\end{array}$ & 20.0 & 80.0 & .03 & 2 & 2001 \\
\hline $\mathrm{ZnO}, \mathrm{SiO}_{2}$ & 22.0 & 90.0 & .025 & 3 & 2721 \\
\hline $\mathrm{SiO}_{2}$, zircon & 22.725 & 77.0 & .025 & 3 & 2172 \\
\hline $\begin{array}{l}\text { Albite, } \\
\text { Tourmaline (all runs) }\end{array}$ & 14.5 & 60.0 & .03 & 3 & 1517 \\
\hline Bauxite & 10.0 & 80.0 & .04 & 4 & 1706 \\
\hline Pure Rutile & 15.0 & 64.0 & .05 & 2 & 981 \\
\hline $\begin{array}{l}\text { Mullite- } \\
\text { Corundum }\end{array}$ & 15.0 & 91.0 & .03 & 2 & 2534 \\
\hline Anatase- & 25.0 & 70.0 & .03 & 1 & 1501 \\
\hline
\end{tabular}

\section{(1) Standard Mixtures}

Table 3 shows the TRACSCAL results for the standard mixtures. The samples were all prepared by weighing in a pillpack, shaking to homogenise and grinding for 5-10 minutes in an agate mortar. The shaking-grinding cycle was repeated five times. Table 3 shows this method gave a constant effective Brindley radius $R$ for all samples of $4-5 \mu \mathrm{m}$, and correct quantification was obtained even when the Brindley correction $\tau$ was extreme (in the case of the $\mathrm{Pb}\left(\mathrm{NO}_{3}\right)_{2} / \mathrm{LiF}$ mixture) or the March orientation parameter $r$ was significantly different from 1 . The quantifications could not have been achieved without these two corrections. The whole $\mathrm{Pb}\left(\mathrm{NO}_{3}\right)_{2} / \mathrm{LiF}$ range has been quantified by TRACSCAL (Taylor and Matulis, 1990); here all samples quantified with $\mathrm{R}=4.3-5.6 \mu \mathrm{m}$, confirming the importance of Brindley corrections and the effective R-value.

These results suggest that, once samples have been prepared in the above manner, then quantification can be found with TRACSCAL, assuming a Brindley radius $R$ of
Table 3.

X-Ray Diffraction Quantitative Analysis Parameters and TRAC SCAL Results for Some Standard Mixtures

\begin{tabular}{|c|c|c|c|c|c|c|c|}
\hline Mixture & $\frac{\mu}{\rho}$ & $\tau$ & $r$ & $\begin{array}{l}\text { Orient } \\
\text { Plane }\end{array}$ & $\begin{array}{c}\mathbf{R} \\
(\mu \mathrm{m})\end{array}$ & $\begin{array}{l}\text { Wei } \\
\text { Actual }\end{array}$ & $\begin{array}{l}\text { ght } \\
\text { TRAC } \\
\text { SCAL }\end{array}$ \\
\hline $\begin{array}{l}\mathrm{LiF} \\
\mathrm{Pb}\left(\mathrm{NO}_{3}\right)_{2}\end{array}$ & $\begin{array}{r}19.8 \\
231.0\end{array}$ & $\begin{array}{l}1.122 \\
0.588\end{array}$ & $\begin{array}{l}1.0 \\
1.0\end{array}$ & - & $\begin{array}{l}4.4 \\
4.4\end{array}$ & $\begin{array}{l}40.0 \\
60.0\end{array}$ & $\begin{array}{l}39.8(3) \\
60.2(3)\end{array}$ \\
\hline $\begin{array}{l}\text { Rutile } \\
\text { Zircon } \\
\text { Ilmenite }\end{array}$ & $\begin{array}{l}190.2 \\
126.5 \\
124.3\end{array}$ & $\begin{array}{l}0.902 \\
1.064 \\
1.054\end{array}$ & $\begin{array}{l}0.79(3) \\
0.669(2) \\
0.667(4)\end{array}$ & $\begin{array}{l}100 \\
100 \\
001\end{array}$ & $\begin{array}{l}5.0 \\
5.0 \\
5.0\end{array}$ & $\begin{array}{l}32.3 \\
35.8 \\
31.9\end{array}$ & $\begin{array}{l}32.4(2) \\
36.0(2) \\
31.1(3)\end{array}$ \\
\hline $\begin{array}{l}\mathrm{ZnO} \\
\mathrm{SiO}_{2}\end{array}$ & $\begin{array}{l}75.1 \\
54.7\end{array}$ & $\begin{array}{l}0.899 \\
1.062\end{array}$ & $\begin{array}{l}1.0 \\
1.0\end{array}$ & - & $\begin{array}{l}4.0 \\
4.0\end{array}$ & $\begin{array}{l}50.7 \\
49.3\end{array}$ & $\begin{array}{l}50.8(1) \\
49.2(1)\end{array}$ \\
\hline $\begin{array}{l}\mathrm{SiO}_{2} \\
\text { Zircon } \\
50 \% \text { mixtur }\end{array}$ & $\begin{array}{r}54.7 \\
126.5 \\
\text { re }^{-}\end{array}$ & $\begin{array}{l}1.101 \\
0.829\end{array}$ & $\begin{array}{l}1.16(5) \\
0.719(3)\end{array}$ & $\begin{array}{l}100 \\
100\end{array}$ & $\begin{array}{l}4.5 \\
4.5\end{array}$ & $\begin{array}{l}49.9 \\
50.1\end{array}$ & $\begin{array}{l}49.9(2) \\
50.1(2)\end{array}$ \\
\hline $\begin{array}{l}\text { Albite } \\
\text { Tour- } \\
\text { maline }\end{array}$ & 51.7 & 1.015 & $0.690(3)$ & 001 & 5.0 & 49.9 & $49.3(2)$ \\
\hline
\end{tabular}

$\frac{\mu}{\rho}$ is the mass absorption coefficient, $\tau$ is the Brindley absorption contrast factor, $r$ is the March preferred orientation parameter, and $R$ is the assumed Brindley particle radius.

$5 \mu \mathrm{m}$ (unless the samples are finer than this initially when the Brindley correction will be less important). The profile fit for the $\mathrm{ZnO} / \mathrm{SiO}_{2}$ mixture is shown in Figure 2. All the other patterns gave similarly good profile-fitting.

\section{Albite-Tourmaline Series}

A series of albite-tourmaline samples, prepared as above, were quantified with TRACSCAL. The first runs gave albite figures which were consistently about a percent too high. Quantification was very good, however, when it was assumed that there was $5 \%$ amorphicity in the tourmaline. The results are plotted in Figure 3 for this series, and shown in Table 4.

Table 4.

TRACSCAL Results for Albite/Tourmaline Mixtures (5\% amorphicity assumed in the Tourmaline. See Also Figure 3)

\begin{tabular}{ccccc} 
Mixture & \multicolumn{2}{c}{ Albite } & \multicolumn{2}{c}{ Tourmaline } \\
& $\begin{array}{c}\text { Wt\% } \\
\text { Actual }\end{array}$ & $\begin{array}{c}\text { Wt } \% \\
\text { TRACSCAL }\end{array}$ & $\begin{array}{c}\text { Wt } \% \\
\text { Actual }\end{array}$ & $\begin{array}{c}\text { Wt } \\
\text { TRACSCAL }\end{array}$ \\
1 & 16.0 & $\mathbf{1 5 . 6 ( 2 )}$ & 84.0 & $84.4(2)$ \\
2 & 34.0 & $34.0(2)$ & 66.0 & $66.0(2)$ \\
3 & 49.9 & $49.3(2)$ & 50.1 & $50.7(2)$ \\
4 & 67.8 & $66.4(3)$ & 32.2 & $33.6(3)$ \\
5 & 84.0 & $84.8(4)$ & 16.0 & $15.2(4)$
\end{tabular}

\section{Other Samples}

a) Natural Bauxite

Table 5 gives results for a bauxite with seven phases in TRACSCAL. The minor phases show significant amounts, and there is some evidence in the difference pattern for further minor phases. $\operatorname{CoK} \alpha$ as used, as the hematite would have a large Brindley correction for $\operatorname{CuK} \alpha$. 
ZNO-S102: $50.7 \%$ AND $49.3 \%$

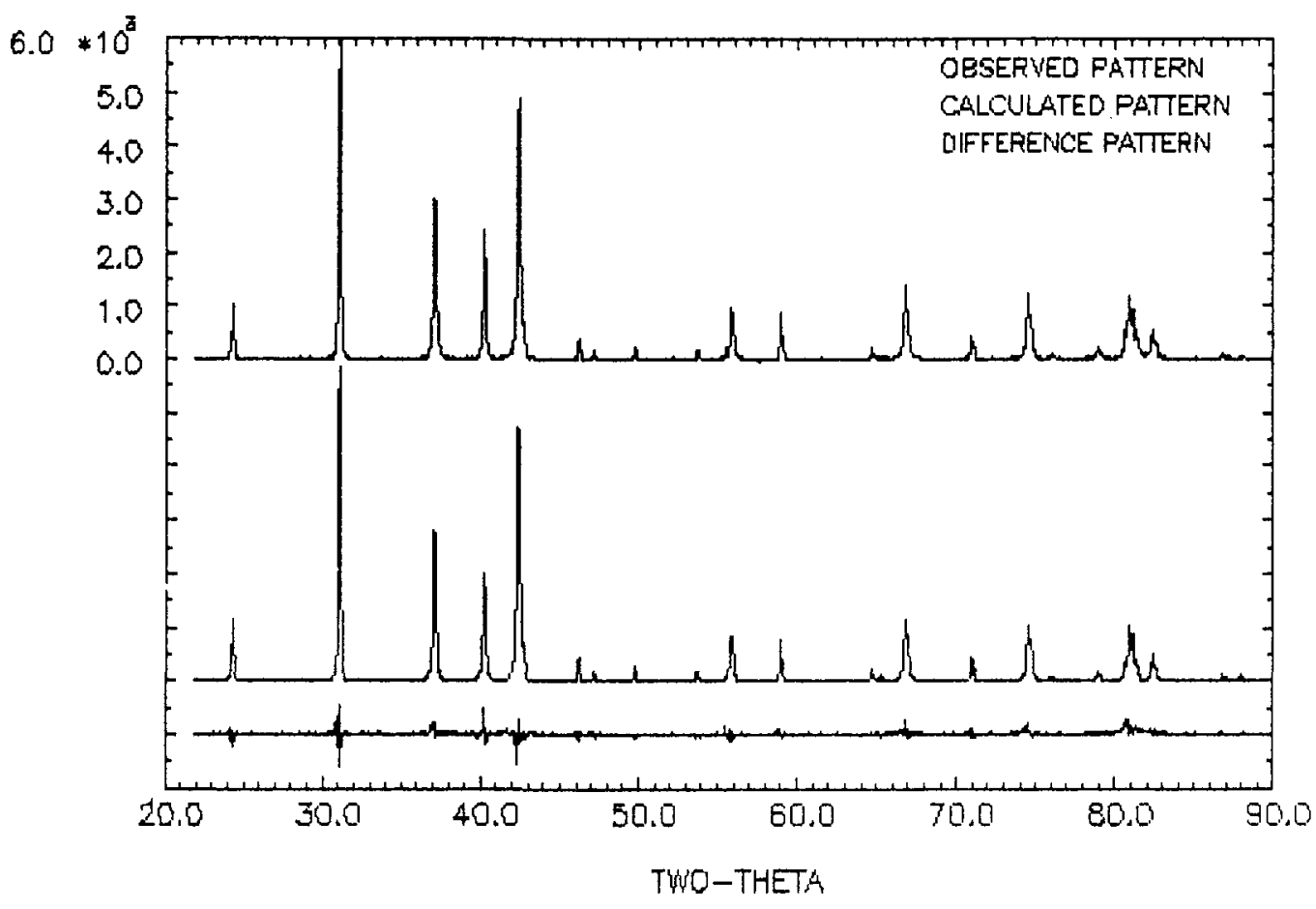

Figure 2. Observed, calculated and difference XRD profiles for $\mathrm{ZnO}-\mathrm{SiO}_{2}$ mixture.

ALBITE,TOURMALINE SERIES

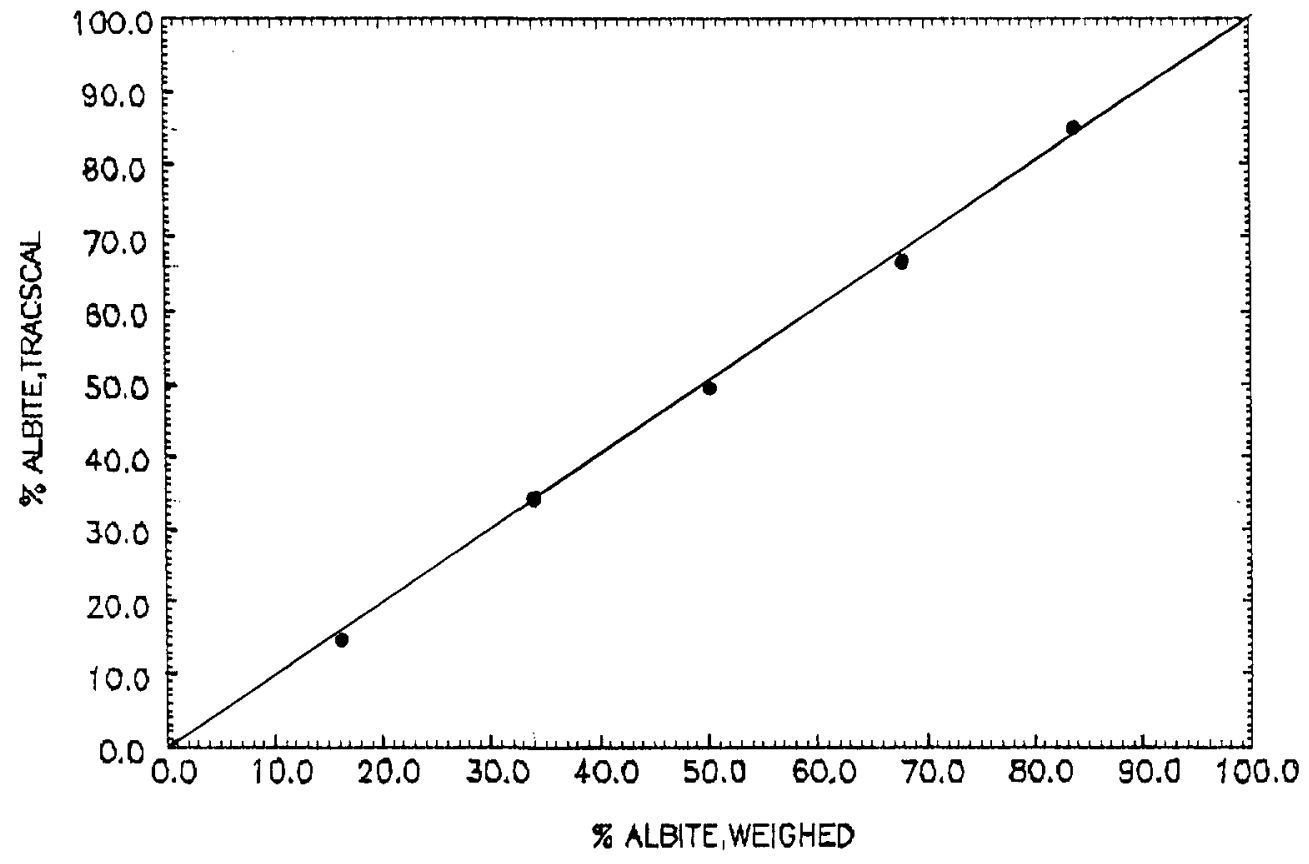

Figure 3. Albite-Tourmaline Series Quantification. 


\section{b) "Pure Rutile"}

Using a scan with a maximum count of only 1000, TRAC SCAL found $1.5(2) \%$ zircon in the rutile (also known from chemical analysis); the zircon peaks are barely visible. The result is shown in Table 5.

\section{c) Mullite-Comindum}

Although the corundum peaks were very weak TRACSCAL found $3.5(4) \%$ corundum in a mullite, (Table 5).

\section{d) Aerosil Titanium Oxide Catalyst (Degussa)}

This is an anatase/rutile mixture produced by high-temperature hydrolysis, with BET surface area $50 \mathrm{~m}^{2} / \mathrm{g}$ and quoted particle size of $30 \mathrm{~nm}$. The lines were quite broad. As the Brindley effect was unimportant for the fine powder, the Brindley $\mathrm{R}$ was set for each phase at $1.0 \mu \mathrm{m}$. The mixture, known to be predominantly anatase, quantified at $75.5(3) \%$ anatase (Table 5).

\section{Table 5.}

X-Ray Diffraction Quantitative Analysis Results for Natural Minerals and Other Samples with Program TRACSCAL

\begin{tabular}{lrccccr} 
Sample & \multicolumn{1}{c}{$\boldsymbol{\mu}$} & $\tau$ & $\mathrm{r}$ & $\begin{array}{c}\text { Orient } \\
\text { Plane }\end{array}$ & $\begin{array}{c}\mathrm{R} \\
(\mu \mathrm{m})\end{array}$ & $\begin{array}{c}\text { Weight \% } \\
\text { (found) }\end{array}$ \\
Hematite & 47.9 & 0.948 & 0.88 & 110 & 5.0 & $27.2(3)$ \\
Boehmite & 43.6 & 1.034 & 1.00 & 001 & 5.0 & $31.4(3)$ \\
Gibbsite & 37.8 & 1.064 & 1.22 & 100 & 5.0 & $30.2(3)$ \\
Quartz & 54.7 & 1.026 & 1.00 & 100 & 5.0 & $1.7(2)$ \\
Anatase & 190.4 & 0.667 & 0.69 & 001 & 5.0 & $5.7(2)$ \\
Rutile & 190.2 & 0.631 & 1.10 & 100 & 5.0 & $1.4(0)$ \\
Maghemite & 47.7 & 0.963 & 1.00 & - & 5.0 & $2.3(2)$ \\
Rutile* & 127.3 & 1.015 & 0.89 & 100 & 1.0 & $98.4(2)$ \\
Zircon & 84.9 & 1.036 & 0.96 & 001 & 1.0 & $1.6(2)$ \\
Mullite & 49.8 & 1.016 & 1.0 & - & 4.0 & $96.5(4)$ \\
Corundum & 48.3 & 0.995 & 1.0 & - & 4.0 & $3.5(4)$ \\
Anatase & 190.4 & 1.106 & 1.0 & - & 1.0 & $75.5(3)$ \\
Rutile & 190.2 & 1.006 & 1.0 & - & 1.0 & $24.5(3)$
\end{tabular}

*"Pure rutile" sample

\section{Importance of the TRACSCAL Amorphicity Corrections}

In non-ideal samples with poor crystallinity, amorphicity corrections may be necessary. A mixture was made up from specimens of clear platy muscovite, orthoclase, quartz, tourmaline and kaolin in the proportions shown in Table 6 (weight $\%$, actual). The specimen of orthoclase was opaque and crumbly, and it was expected to have some amorphous component. The kaolinite was a local preparative sample and expected to have amorphous content also. The quartz, tourmaline and muscovite were better (museum) specimens. A quantification run with TRACSCAL assuming zero amorphicity in each phase gave the weight percentages given in Table 6 (TRACSCAL Run 1). The fit of the observed and calculated patterns was quite good, and is, of course, independent of the amorphicities assumed. However, the quantification was not good, with TRACSCAL giving a high weight percentage for quartz and a low percentage for orthoclase and kaolin.

It appeared that the orthoclase and kaolin possibly had considerable amorphous content. Mixtures of the pure kao-

lin and orthoclase were made up with a quartz spike (50:50), and patterns collected with $\operatorname{CoK} \alpha$ radiation. The fits for the orthoclase $/ \mathrm{SiO}_{2}$ and kaolin $/ \mathrm{SiO}_{2}$ were quite good but quantification was only obtained by assuming $54 \%$ amorphous content in the kaolin and $40 \%$ in the orthoclase. Some of the kaolin "amorphicity" may be, in fact, a compensation for misfit due to assumption of an ordered kaolin crystal structure.

When the five-phase pattern calculation was rerun, this time with $54 \%$ and $40 \%$, amorphicities assumed for kaolin and orthoclase, then the TRACSCAL quantification was quite good (TRACSCAL Run 2, Table 6).

This example illustrates the importance of checking the amorphicities of standard pure phases where possible by spiking them with another phase of low amorphicity.

Table 6.

TRACSCAL Results for Muscovite- Orthoclase- Quartz- Tourmaline- Kaolin Mixture

Phase

$\mathrm{Wt} \%$
TRACSCAL Run 1

Wt\%
TRACSCAL Ru
$24.3(3)$
$12.8(2)$
$16.9(1)$
$22.5(3)$
$23.4(2)$

$\mathrm{Wt} \%$

Muscovite 28.9

Orthoclase

Quartz

9.1

20.7

27.7

Kaolin

13.4

$23.4(2)$

Actual

15.2

15.2

21.7

TRACSCAL Run 1: All phase amorphicity factors zero.

TRACSCAL Run 2: $54 \%$ amorphicity assumed in kaolin and $40 \%$ in orthoclase, all other phases zero amorphicity. The quantification is better when amorphicities are assumed.

\section{TRACSCAL Computing Times}

Table 7 shows the times for one scaling cycle with TRACSCAL for the various patterns on a $20 \mathrm{MHz}-\mathrm{AT}$ personal computer. The time includes pattern input, processing of phase $(\mathrm{hk} l$ ) files, profile calculations, and least-squares adjustment of the variable parameters. The Lucas Heights IBM mainframe computer is approximately seven times faster than the AT machine.

\section{Table 7.}

Computing Times for TRACSCAL Runs (1 cycle) on a $20 \mathrm{MHz}$ AT Personal Computer. (Typical mainframe times would be 7 times faster.)

Sample

$\mathrm{LiF}, \mathrm{Pb}\left(\mathrm{NO}_{3}\right)_{2}$

Rutile, Zircon,

Ilmenite

$\mathrm{ZnO}, \mathrm{SiO}_{2}$

$\mathrm{SiO}_{2}$, Zircon

Albite, Tourmaline

Bauxite

"Pure" Rutile

Mullite, Corundum

Anatase, Rutile

Number of
Independent
$(\mathrm{hk} l)$ in
Pattern, N

65

76

72

73

163

320

28

75

19
Time for 1 TRACSCAL Cycle Refining Scales, $\mathrm{T}$ (sec)

$\begin{array}{rl}30 & 2.2 \\ 35 & 2.2 \\ & \\ 31 & 2.3 \\ 30 & 2.4 \\ 47 & 3.5 \\ 145 & 2.2 \\ 14 & 2.0 \\ 37 & 2.0 \\ 23 & 0.8\end{array}$




\section{Residuals}

The residuals for the observed and calculated patterns are given in Table 8 . The R-factors on the pattern heights $y$ (profile $\mathrm{R}$ factors) are between 0.2 and 0.3 , while the normalised goodness of fit criterion, which theoretically approaches unity, lies between 0.64 and 3.62. As defined in Table 8 , the unweighted profile $\mathrm{R}$-factor is larger than singlecrystal R-factors because it is based on $\mathrm{F}(\mathrm{hk} l)^{2}$ and not $\mathrm{F}$ $(\mathrm{hk} l$ ). Also, the copious amount of "weak" data is included. In practice, it is difficult to reduce the unweighted profile $\mathrm{R}$ factor, as defined here, below about 0.15. Quite a good fit with $\mathrm{R}$ (profile) $=0.20$ is obtained, as shown in the $\mathrm{ZnO}$ / $\mathrm{SiO}_{2}$ pattern fit, Figure 2. All patterns showed good profile fits.

Table 8.

Profile Residuals

Sample

$\mathrm{LiF} / \mathrm{Pb}\left(\mathrm{NO}_{3}\right)_{2}$

Rutile, Zircon

Ilmenite

$\mathrm{ZnO}, \mathrm{SiO}_{2}$

$\mathrm{SiO}_{2}$, Zircon

Albite, Tourmaline 1

Albite, Tourmaline 2

Albite, Tourmaline 3

Albite, Tourmaline 4

Albite, Tourmaline 5

Bauxite

"Pure" Rutile

Mullite, Corundum

Anatase, Rutile

Profile R*

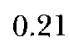

0.26

0.20

0.23

0.22

0.28

0.25

0.25

0.26

0.28

0.28

0.28

0.31
* Profile $R=\frac{|\mathrm{Yo}-\mathrm{Yc}|}{\sum|\mathrm{Yo}|}$

$+C H I S Q=\left(\sum \frac{(\mathrm{Yo}-\mathrm{YC})^{2}}{\mathrm{Yo}(\mathrm{NO}-\mathrm{NV})}\right)^{1 / 2}$

Yo and Yc are background-corrected profile point heights, and (NO-NV) is the number of degrees of freedom. All pattern points, whether they have reflection contributions or not, are included.

\section{Conclusion}

This paper describes an integrated set of computer programs which were developed for standardless quantitative phase analysis of minerals using the complete multiphase diffraction profile. The programs, in Fortran 77, run on an IBM mainframe or IBM compatible personal computers. Special features include corrections for Brindley absorption contrast, preferred orientation and phase amorphicity. The programs obviate the need for preparation and collection of intensity patterns for pure phase reference standards, except in amorphicity determinations.

\section{Acknowledgements}

The author wishes to thank Dr J. Barry, Mr R. Cawley and Dr J.P. Pollard for helpful advice on computing, Mr C. E. Matulis for preparing the $\mathrm{Pb}\left(\mathrm{NO}_{3}\right)_{2} / \mathrm{LiF}$ sample and obtaining x-ray pattern data, Mr R. Freeman of SIETRONICS, Pty Ltd for the mullite, rutile and zircon specimens, Mr I. Gough of AMC Mineral Sands for the pure rutile specimen, Mr A.B. Waugh for mineral specimens and advice and Mr S. Frederickson and Dr B. Clancy for help in implementing plot routines. I also wish to thank Dr P.G. Alfredson, Mr L.S. Dale and Mr W.R. Vickery for helpful comments and advice.

\section{References}

Bish, D.L. \& Howard, S.A. (1988). J. Appl. Crystallogr., 21, 86-91

Brindley, G.W. (1945). Phil. Mag., 36, 347-369

Dollase, W.A. (1986). J. Appl. Crystallogr., 19, 267-272

Hall, M.M., Veeraraghavan, V.G., Rubin, H. and Winchell, P.G. (1977). J. Appl. Crystallogr., 10, 66-68.

Hamilton, W.C. (1964). Statistics in Physical Science, Ronald Press, New York

Hewat, A.W. (1973). Harwell Report 73/239 and Ill. Report 74/ H625.

Hill, R.J. \& Howard, C.J. (1986). AAEC Report M112, Lucas Heights Research Laboratories, Menai, NSW Australia.

Hill, R.J. \& Howard, C.J. (1987). J. Appl. Crystallogr., 20, 467-474.

Howard, C.J., Hill, R.J. \& Sufi, M.A.M. (1988). Chemistry in Australia, 55, 367-369.

Klug, H.P. \& Alexander, L.E. (1974). X-Ray Diffraction Procedures for Polycrystalline and Amorphous Materials. New York: Wiley and Sons.

Nuffield, E.W. (1966). X-Ray Diffraction Methods. New York: Wiley and Sons.

Rietveld, H.M. (1969). J. Appl. Crystallogr., 2, 65-71.

Sheldrick, G. (1976) Shelx-76 program system, University of Cambridge.

Smith D.K., Johnson G.G., Scheible, A., Wims; A.M., Johnson, J.L., \& Ullman, G. (1987). Pow. Diff., 2, 73-77.

Taylor, A. (1961). X-Ray Metallography, Wiley: New York, p.259-263 and Table 76.

Taylor, J.C. (1978). Report AAEC/E436, Lucas Heights Research Laboratories, Menai, NSW, Australia.

Taylor, J.C. (1980) Report AAEC/E488, Lucas Heights Research Laboratories, Menai, NSW, Australia

Taylor, J.C. (1987a) Zeolites, 7, 311-318.

Taylor, J.C. (1987b) Z. Krist, 181, 151-160.

Taylor, J.C., Kelly, J.W. \& Downer, B. (1972). J. Solid State Chem., 5, 291-299.

Taylor, J.C. \& Matulis, C.E. (1990). J. Appl. Crystallogr., submitted.

Taylor, J.C., Miller, S.A., \& Bibby, D.M. (1986). Z. Krist., 176, 183192.

Toraya, H., Yoshimura, M., \& Sorriya, S. (1984). J. Amer. Ceram. Soc., 67, C119-C121.

Wilchinsky, Z.W. (1951). Acta Cryst., 4, 1-9.

Wiles, D.B., \& Young, R.A. (1981) J. Appl. Crystallogr., 14, 149-151.

Will, G., Parrish, W., \& Huang, T.C. (1983). J. Appl. Crystallogr., 26, $611-622$.

de Wolff, P.M. (1947). Physica, 13, 62.

Received May 31, 1990

Revised November 6, 1990

Accepted November 10, 1990 